Independent Panel for Pandemic

Preparedness and Response

Correspondence to: Sudhvir Singh Singhsu@ipppr.org

Cite this as: BMJ 2021;375:n2914 http://dx.doi.org/10.1136/bmj.n2914 Published: 29 November 2021
COVID-19 PREPAREDNESS AND RESPONSE: IMPLICATIONS FOR FUTURE PANDEMICS

\section{Ending this pandemic and securing the future}

\author{
Act quickly and collectively to transform global systems for preparedness and response \\ Helen Clark, Ellen Johnson Sirleaf
}

In December it will be two years since the first cases of covid-19 were identified in Wuhan, China, and one year since the first clinical trial results showed that the world had developed an effective vaccine. In May 2021, The Independent Panel for Pandemic Preparedness and Response put forward a package of vital reforms required to end the current pandemic and better secure the future. ${ }^{1}$ Six months later, is the world is better placed to respond to future pandemics or indeed to end this current one?

The short answer is no. There are reasons for optimism in some areas, but the urgency and pace of change does not meet the needs of the moment-to respond quickly and effectively to a disease that has killed more than five million people worlwide. ${ }^{2}$ The world is still dangerously unprepared for the next pandemic threat. This collection of nine papers draws on the analytical work that contributed to the panel's recommendations. Together, this collection shows how, why, and where the world and individual countries succeeded or failed against covid-19 and points to solutions that can end the covid-19 pandemic and make it the last pandemic of such devastation.

Key opportunities for progress have been squandered. The recent G20 meeting in Italy failed to deliver. Rather than urgently redistributing vaccine doses and delivering financing for pandemic preparedness, the outcome was yet another task force. ${ }^{3}$

Our panel report in May called for one billion vaccine doses to be redistributed from high income to low income countries by 1 September. High income countries have failed to meet that target. ${ }^{4}$ While wealthy countries roll out booster programmes, low and middle income countries' ability to purchase vaccines is being squeezed: at the time of writing, fewer than $5 \%$ of people in low income countries had received a single dose. ${ }^{5}$ Prime Minister Mia Mottley of Barbados has asked the right question of her fellow heads of government: "How many more deaths must it take before the ... excess vaccines in the possession of the advanced countries of the world will be shared with those who [have] simply no access to vaccines?"

But, although vaccines are vital, they alone will not end the current pandemic. Waves of infection and death continue to batter many of the most vulnerable people in rich and poor nations alike. The world must make use of the full range of tools currently available-both within and beyond the health sector. Novel antiviral agents are reported to reduce the risk of hospital admission and death for people with covid-19 and can serve as additional tools in the world's arsenal, also helping to move us from pandemic to endemic management, but only if they are shared equitably.

We must take collective action now to end the current pandemic. This is also the moment to strengthen the international architecture of preparedness and response, building resilience to this and future

Rather than allowing geopolitical posturing to stall progress, the world needs leaders to come together and set out their collective response to this historic challenge by convening a special session of the UN General Assembly to commit to transforming the global system for preparedness and response.Covid-19 has shown that health emergencies have an impact that goes far beyond the health sector. The deep scarring of sectors across societies and economies shows that response and recovery need whole-of-society and multisectoral responses. Our May report proposed a Global Health Threats Council as a way of bringing the necessary high level political leadership to this challenge and to unify action internationally. If linked to a financial mechanism, this leadership body could direct funding to where it's needed to ensure truly global coverage of preparedness and response.

At the heart of any effort to strengthen global capacity to prevent and respond to pandemics must be a stronger, financially secure, and more authoritative World Health Organization. We hope the the World Health Assembly will make haste on a pandemic treaty: to fail to do so would be to miss yet another opportunity for vital reforms to ensure that WHO can detect and alert the world to future threats more quickly. The Member State Working Group on strengthening WHO preparedness and response to health emergencies has discussed several of the independent panel's recommendations, and these must now be taken up by WHO governing bodies.

Pandemics are not ended by a magic bullet, but by a combination of essential measures: leader level commitment, finance, equitable access to global public goods, new legal instruments, and a stronger and more authoritative WHO. The world cannot afford to wait another six months to begin delivering on vital reforms which could make covid-19 the world's last pandemic.

Provenance and peer review: Commissioned; not peer reviewed. threats. 
Competing interests: We have read and understood BMJ policy on competing interests and declare the following: none

This collection of articles was proposed by The Independent Panel for Pandemic Preparedness and Response, open access fees were funded by WHO and Singapore's National Medical Research Council (NMRC/CG/CO26/2017_NUHS). The BM/commissioned, peer reviewed, edited, and made the decision to publish these articles. Kamran Abbasi was the lead editor for The BMJ.

1 Independent Panel for Pandemic Preparedness and Response. Covid-19: make it the last pandemic. May 2021. https://theindependentpanel.org/2021

2 Institute for Health Metrics and Evaluation. Covid-19 projections. https://covid19.healthdata.org/global?view=cumulative-deaths\&tab=trend

3 Independent Panel for Pandemic Preparedness and Response. G20 Summit covid-19 outcome deeply disappointing. 1 November 2021. https://theindependentpanel.org/g20-summit-covid-19outcome-deeply-disappointing/

4 International Monetary Fund. The IMF-WHO vaccine supply forecasts dashboard. 22 November 2021. https://www.imf.org/en/Topics/imf-and-covid19/COVID-Vaccine-Supply-Forecast

5 Our World in Data. Coronavirus (COVID-19) Vaccinations-statistics and research. https://ourworldindata.org/covid-vaccinations

6 United Nations Foundation. Nine quotes we'll remember from UNGA 76. 28 September 2021. https://unfoundation.org/blog/post/nine-quotes-well-remember-from-unga-76/

7 Merck. Merck and Ridgeback's investigational oral antiviral molnupiravir reduced the risk of hospitalization or death by approximately 50 percent compared to placebo for patients with mild or moderate covid-19 in positive interim analysis of phase 3 study. https://www.merck.com/news/merck-and-ridgebacks-investigational-oral-antiviral-molnupiravir-reduced-the-riskof-hospitalization-or-death-by-approximately-50-percent-compared-to-placebo-for-patientswith-mild-or-moderat/

This is an Open Access article distributed under the terms of the Creative Commons Attribution IGO License (https://creativecommons.org/licenses/by-nc/3.0/igo/), which permits use, distribution, and reproduction for non-commercial purposes in any medium, provided the original work is properly cited. 